\title{
Using Technology to Eliminate Traffic Congestion
}

\author{
Comment \\ by \\ Friedrich Breyer* \\ 1 Introduction
}

These are a layman's comments. So the reader should not expect more than a little bit of economic common sense.

Road space is a scarce commodity. Therefore it makes sense to consider whether its allocation via the price mechanism can enhance efficiency relative to the allocation through waiting lines. The topic also fits well within the conference theme "Without Money," because the authors propose shifting the scarce good road use from the sphere "without money" to the sphere "with money."

According to the authors, road pricing can have the following purposes:

(1) achieving a more efficient allocation of the scarce good,

(2) mitigating congestion and thereby reducing negative externalities,

(3) collecting funds for road repair, maintenance, and construction.

I agree with the authors that the current system of allocating scarce road space is particularly wasteful and therefore pricing has a great potential of making life easier for most users of roads.

\section{Types of Road Pricing and their Feasibility}

To better understand and evaluate the authors' proposal it is useful to distinguish two types of road pricing:

(a) Prices for the use of specific bottlenecks (bridges, tunnels, access roads to cities): these user prices may vary over time, but are not responsive to demand changes in real time. This is a type that already exists in particular in Singapore, London, Oslo, Stockholm, and other big cities.

(b) Dynamic pricing with advance booking and scheduling for specific segments of roads. This is the new type envisaged by the authors.

\footnotetext{
* University of Konstanz, Germany.
} 
We know dynamic pricing from other areas of life, such as seats in theaters or concerts, airline tickets, or parking space at airports. It also applies to electricity. Therefore, to judge whether the pricing principles can be translated from these domains to roads we have to ask whether the properties of demand for these goods are comparable.

The commodity being traded here is the right to use a well-defined section of a road (say, $5 \mathrm{~km}$ ) within a specific time slot, e.g. a 10-min interval, so each item is a particular (road section, time) vector (Cramton, Geddes, and Ockenfels, 2019, section 3). This is at least true of the wholesale market in which so-called independent systems operators (ISOs) trade. Service providers then have the task to sell trips to retail customers, the motorists. A trip consists in the right to travel from a certain starting point (e.g., the home of the motorist) to a destination (the workplace) at a particular time on a particular day (or regularly: every weekday within a month, etc.).

Here I already see the first difficulty in that the ISO must translate a set of road use rights, which it owns, into a number of feasible trips, which it can sell, without creating congestion. Even if this is technically possible, it seems to require very strict rules to avoid frictions, e.g., with respect to compliance of the customers: How much time is the customer allowed to start his trip earlier or later? ${ }^{1}$

I can imagine that this problem can be solved for trips that are not too long and that can easily be scheduled, as are typical commutes between home and workplace - in particular, in metropolitan areas where there are a limited number of access roads to a city center in which many workplaces are located. In fact, this type of road pricing (of type (a), however) already exists in the mentioned cities, and it would be refined using the tools described by the authors. To say it bluntly, they have chosen to pick the low-hanging fruit first, which is all too understandable.

But many traffic jams form on long stretches of motorways, often far away from big cities, sometimes due to roadwork, but often just through an excessive amount of traffic. Suppose the same pricing principle (for 5-km sections of a motorway and 10-min time intervals) is applied by an ISO, and consider a family wanting to go on a holiday trip of $500 \mathrm{~km}$ on a particular day. The authors write: "Absent road pricing, drivers face uncertainty about trip time" (Cramton, Geddes, and Ockenfels, 2019, section 4.1, emphasis added). But with road pricing, the same holds true if we look, e.g., at the bottleneck that usually occurs between $\mathrm{km} 400$ and 410 on this trip. In which time interval the family is able to "demand" driving along this section depends on a number of things: the existence of any traffic jams on the first $400 \mathrm{~km}$, the length of any rest periods, the speed with which they were able to drive, and many more. In short, there is not only genuine demand uncertainty, but the demand for any given part of the trip depends upon the extent to which demands for earlier parts were met. In the working-paper version (Cramton, Geddes, and

\footnotetext{
${ }^{1}$ Here one may add that the main advantage of car use over public transport, namely the flexibility in choosing the exact time of departure, is lost in the case of strict rules, so that, as everywhere, there is a trade-off between two reasonable goals of the consumer.
} 
Ockenfels, 2018, p. 22), the authors admit that "there are many interrelated products." This makes highway driving a fundamentally different good from parking space or concert seats. And the comparison with electricity is equally misleading because, absent strict speed limits, road use is a much more heterogeneous good than electricity.

\section{Fees and Other Mechanisms for Avoiding Traffic Jams}

In their Conclusion, the authors describe how they expect real-time road pricing to evolve as an allocation device over time: "Prices on congested road segments are set to induce demand to eliminate the congestion and maximize throughput. Userfriendly computer apps armed with this price information then guide consumers in making transport choices consistent with their preferences" (Cramton, Geddes, and Ockenfels, 2019, section 5). I imagine driving in my car from Bonn to Berlin and that in approaching Hannover, the app tells me that staying on the A2 motorway will cost me additional 10 euros because the segment between Hannover and Braunschweig is congested. If I used a detour via a lower-grade highway, I could avoid this cost.

Now compare this with the present world in which I have a traffic app built into my car that marks the corresponding stretch on the $\mathrm{A} 2$ in red, and the radio tells me that I have to expect a delay of $30 \mathrm{~min}$ if I stay on the motorway. Sometimes my navigator even tells me right away to leave the $\mathrm{A} 2$ and gives me concrete directions that lead me around the congested segment. I admit, these devices are not perfect, and I do not have to pay a fine for the congestion costs that I impose on others, but it is hard for me to imagine that the additional monetary costs will be the essential missing link between the desire of motorists to avoid traffic jams and the achievement of this goal.

Again, and similarly to the commuter case, it is conceivable that for particular segments of particular highways that are typically congested on particular days in the year (e.g., the motorway A8 between Stuttgart and Ulm on the first day of the summer school holidays in North Rhine-Westphalia) a system of advance booking and a very high price of using it without such a permit could avoid the most severe traffic jams; but it is hard to see how this principle could be extended to address all the other cases of traffic jams, some foreseen but most others unforeseen, that develop on our roads.

\section{Concluding Remarks}

The authors should be applauded for having pointed out a source of severe inefficiencies under which almost all citizens in developed (and probably also less developed) countries suffer, and for suggesting the use of the price system as a potential way to attenuate these problems. 
Again in the working-paper version (Cramton, Geddes, and Ockenfels, 2018, p. 35), they advise an "incremental approach to road pricing in Singapore," in which a 7-step transition to real-time pricing is described. The text concludes with the assertion: "Because the transition is done in incremental steps, and the benefits of each single step are constantly measured and monitored, the technological and policy risks of the transition to the most efficient end state for road pricing are mitigated" (p. 38). All this refers to Singapore, a city-state with an area of $700 \mathrm{~km}^{2}$ and a population density of almost 8,000 per square kilometer - again a low-hanging fruit.

My own conclusion from this exercise is that in the foreseeable future we will see more road pricing of the already existing type, i.e., pricing of bottlenecks around and within metropolitan areas. In contrast, it is a long way towards a large-scale implementation of the type of dynamic pricing and scheduling envisaged by the authors.

\section{References}

Cramton, Peter, R. Richard Geddes, and Axel Ockenfels (2018), "Markets for Road Use: Eliminating Congestion through Scheduling, Routing, and Real-Time Road Pricing," Working Paper, January 22, http://www.cramton.umd.edu/papers2015-2019/cramtongeddes-ockenfels-markets-for-road-use.pdf, accessed November 3, 2018.

- , - , and - (2019), "Using Technology to Eliminate Traffic Congestion," Journal of Institutional and Theoretical Economics (JITE), 175(1), 126-139.

Friedrich Breyer

Department of Economics

University of Konstanz

Box 135

78457 Konstanz

Germany

friedrich.breyer@uni-konstanz.de 